\title{
A citation history of measurements of Newton's constant of gravity
}

\author{
Katelyn Horstman ${ }^{1} \cdot$ Virginia Trimble ${ }^{2}$
}

Received: 21 December 2018 / Published online: 19 February 2019

(c) The Author(s) 2019

\begin{abstract}
We created and analyzed a citation history of papers covering measurements of Newton's constant of gravity from 1686 to 2016. Interest concerning the true value of the gravitational constant was most intense in the late 90 s to early 2000s and is gaining traction again in the present. Another network consisting of the same papers was created using citations from databases to display the prominence of papers on Newton's constant in the wider scientific community. In general, papers that were important in one network remained important in the other while papers that had little importance in one network remained unimportant in the other. The US contributes the most to literature on the topic both in where journals were published and where the work was done; however, many other countries, such as China, Russia, France, Germany, Switzerland, and the UK also provide many papers on Newton's $G$. Work done within certain countries tends to be considered more important and cited more often within that country. Recent efforts promoting international collaboration may have an impact on this trend.
\end{abstract}

\section{Introduction}

In 1789, Henry Cavendish was to use the first torsion balance to measure the strength of gravitational interaction. After his initial success, many others explored methods of measuring the gravitational constant, either by modifying his experiment or seeking better ones. However, even with experimentation and concern for finding the true value of the constant over the past few centuries, Newton's constant remains elusive. It is by far the least well known of the fundamental constants of physics. Measurements from a handful of differing experiments - even more recent measurements-have discrepancies of up to .05\%, leading to large uncertainty in the true value of the constant. Researchers agree on at most the first three significant figures, or that $G=6.67 \times 10^{-11} \mathrm{~N} \times \mathrm{m}^{2} / \mathrm{kg}^{2}$.

Katelyn Horstman

katelynhorstman@gmail.com

Virginia Trimble

vtrimble@astro.umd.edu

1 Department of Physics and Astronomy, University of California Los Angeles, Los Angeles, CA 90024, USA

2 Department of Physics and Astronomy, University of California Irvine, Irvine, CA 92697, USA 
The uncertainty associated with Newton's gravitational constant is concerning because gravity is the most easily experienced and most recognizable fundamental force of nature. A very precise value could be a hint of some physics beyond general relativity. It is notoriously tricky to measure for of three reasons. First, gravity is an extremely weak force compared to other measured forces such as electromagnetic or nuclear forces. For a proton and an electron, the ratio of the electromagnetic to the gravitational force is given by $\frac{F_{\mathrm{EM}}}{F_{\mathrm{G}}}=\frac{e^{2}}{4 \pi \varepsilon_{0} G m_{\mathrm{p}} m_{\mathrm{e}}}=10^{40}$, where $e$ is charge on the electron, $G$ is Newton's constant, $m_{\mathrm{p}}$ is the mass of the proton, and $m_{\mathrm{e}}$ is the mass of the electron. Second, $G$ is not tightly coupled in with the constants of electromagnetism and quantum mechanics in the way that the mass and charge of an electron are. And third, all measurements of Newton's gravitational constant have had to be done very close to a large, interfering mass-Earth. In 2016, the National Science Foundation began a quest for a more precise value of "Big $G$ ". They convened a workshop at NIST (National Institute for Standards and Technology) to propose and discuss novel measurement techniques to resolve discrepancies and lead to a more precise value for $G$. One of us, Virginia Trimble, was a participant.

In this paper, we explore the relationship between papers searching for or discussing the importance of Newton's gravitational constant. Dating from Newton in 1686 to efforts in 2016, the citation map created shows some of the most important relationships between literature published on Newton's constant within the past few centuries and the resources those papers used for inspiration. The citation map helps identify which papers are the most influential within the community. We aim to discover whether members within this community are receiving the credit they deserve or if other members are overrepresented. We also intend to see if countries in which the work was done or journals in which the papers were published in affect the amount of influence a paper has.

Katelyn Horstman thought of looking for correlations with gender but discovered that the use of initials often made this impossible to determine and we suspect that there are very few women authors in this network.

Stephan Schlamminger, a physicist at the National Institute of Standards and Technology (NIST), kindly gave Virginia Trimble a flash drive consisting of the papers he deemed important concerning Newton's gravitational constant. She concluded that some sort of citation analysis, grouping publications and using citations from outside the group, would be useful. We created the citation analysis using around 220 of the roughly 300 original papers from the flash drive. The 80 or so papers not used did not help build the network as they either did not cite papers within the list or consisted of papers with no citations at all. We created another network consisting of the same papers, but each paper's graphical representation was based the number of times it was cited within the scientific community.

\section{Methods}

We used an excel spreadsheet to document and cite the papers within the network. Each paper in the network either cited another paper within the network or was cited by another paper within the network. We formatted the sources and their citations to establish relationships between papers then uploaded the created relationships to a citation analysis program called Gephi. Gephi created a citation network graphically showing the relationship among papers.

Each paper was assigned a number, listed in the "Appendix" section, and then ordered chronologically on the diagram. Lines connecting different numbers show which papers cited other papers and the direction is indicated with small arrows pointing toward the 
paper that was cited. The larger the number appears in the diagram, the more times that paper was cited. In addition, most frequently cited papers are purple, moderately cited papers are yellow, and least frequently cited papers are white. The network shown displays the relationship between various methods of calculating Newton's gravitational constant and other papers documenting its importance or history.

\section{Data}

Figure 1 shows how many times each paper in the network was cited by another paper in the network. As predicted, recent papers cite older papers more frequently. In the late $90 \mathrm{~s}$ to early 2000s showed a surge in notable papers concerning Newton's $G$. The next wave of papers occurs in 2014. Physicists from around the world met at the Royal Society in London and published many findings-perhaps helping renew the National Science Foundation's interest in finding a better value for Newton's gravitational constant.

Looking at the shape of the network itself, we found that the number of papers starts small, grows large in the middle, then gets small again when it approaches more recent times. The smaller number of papers published in 2016 could indicate not knowing which papers will be important in future instead of a lack of interest in the topic.

After reviewing the connections made in the network, we decided we wanted to investigate the importance of each paper in the greater scientific community. Using the Astrophysics Data System and the Web of Science databases, we used the number of times each paper was cited to resize and recolor the circles based on their importance in all fields. Figure 2 shows the results.

In general, papers that were important in Fig. 1 remained important in Fig. 2 and the papers that could not be found have little importance in both figures. Papers from almost all time periods remain important to scientists based on their citation history. A larger number of papers in Fig. 2 have a substantial number of citations. Some of the larger circles in Fig. 2 have more than 400 citations while the larger circles in Fig. 1 have fewer than 100 citations due to the size of the network.

\section{Analysis}

After creating the citation networks in Figs. 1 and 2, we decided to look more deeply at the countries associated with the journals the papers were published in.

Figure 3 shows the US journals dominate where scientists publish their results on Newton's gravitational constant. The UK, Russia, and countries in Continental Europe all have a moderate number of papers published in their respective journals while countries such as China have few papers published on Newton's $G$. However, the country associated with the journal is not always the same as the country where the work was done.

Figure 4 shows the slight discrepancy between countries where the work was done versus what country the journal is associated with after the paper was published. Although most of the work was done in the US, there are still a significant number of papers published in US journals even though the work was done in different countries. For quite a few papers, the work was done in either Continental Europe or other countries not listed in Fig. 4, but the papers were published in US journals. Many papers where experiments were carried out in China published their result in either US or UK journals. We speculate this 


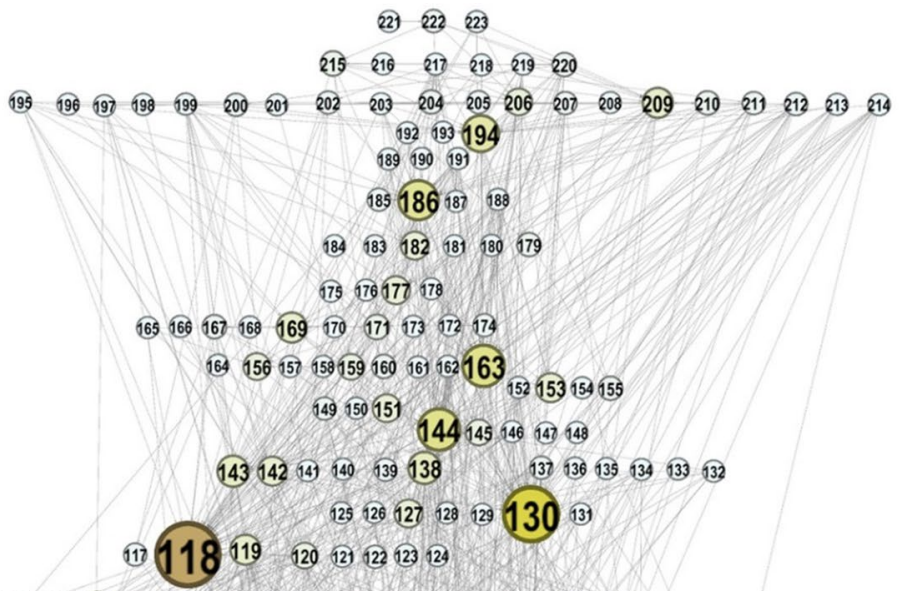

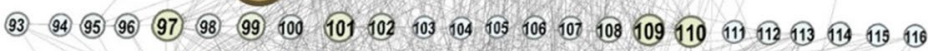
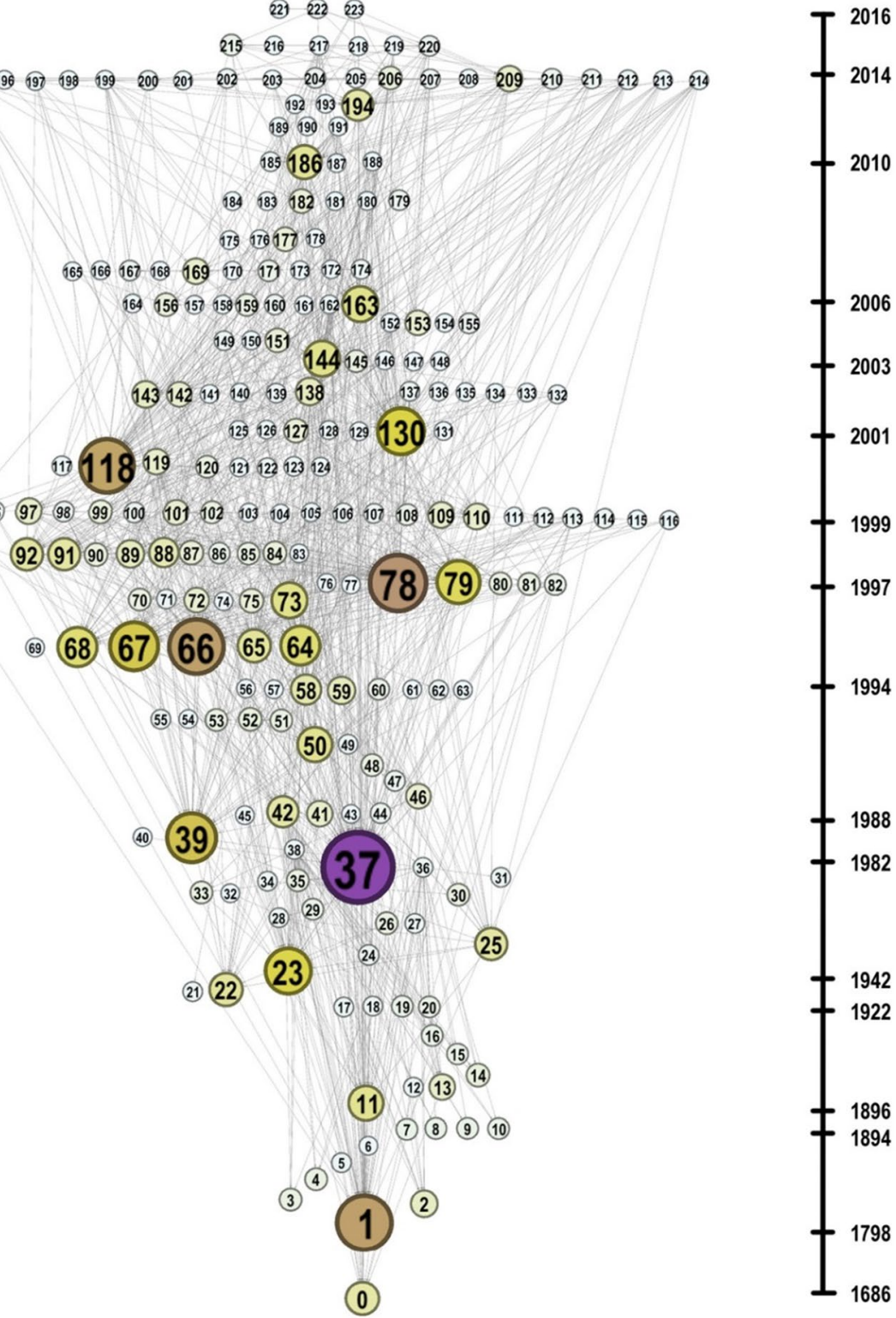

Fig. 1 A citation network showing the relationship between papers influential in studying Newton's gravitational constant. Each line shows a connection between two papers and is numbered in Table 1

could be due to the regular interest the US and UK have had in Newton's constant starting in the early 1900s and continuing until the present.

World War II was another barrier when measuring Newton's gravitational constant. Figure 5 shows the country the work was done in before 1938, or the beginning of World War II, while Fig. 6 shows the country the work was done in after 1938.

Figures 5 and 6 show the overall increase in interest in Newton's constant after 1938. Before 1938, the UK, not the US, published the largest number of significant papers 


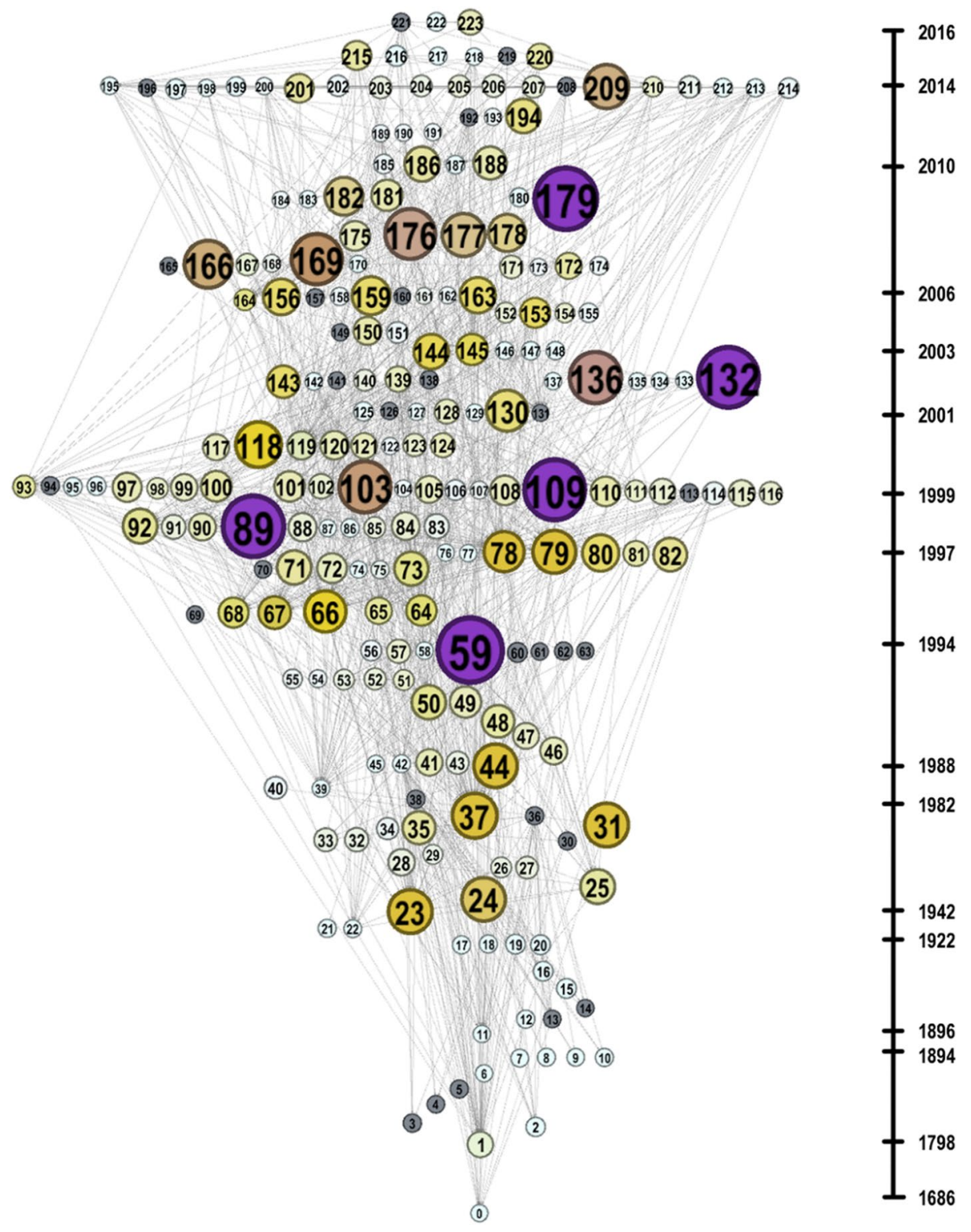

Fig. 2 A citation network showing the relationship between papers influential in studying Newton's gravitational constant. Each paper's size and color are based on how often the paper was cited in the scientific community. The smaller, gray circles represent papers not found in a database. The original connections between papers from Fig. 1 remain

regarding $G$. However, after 1938, the US dominates where the work was done. Looking more closely at Continental Europe, all the papers published before 1938 described that the work was done in Germany. After 1938, Continental Europe showed a renewed interest in Newton's constant, but the work was mostly done in countries other than Germany, as illustrated by Fig. 9. Russia and other countries not listed in Figs. 5 and 6 did publish 


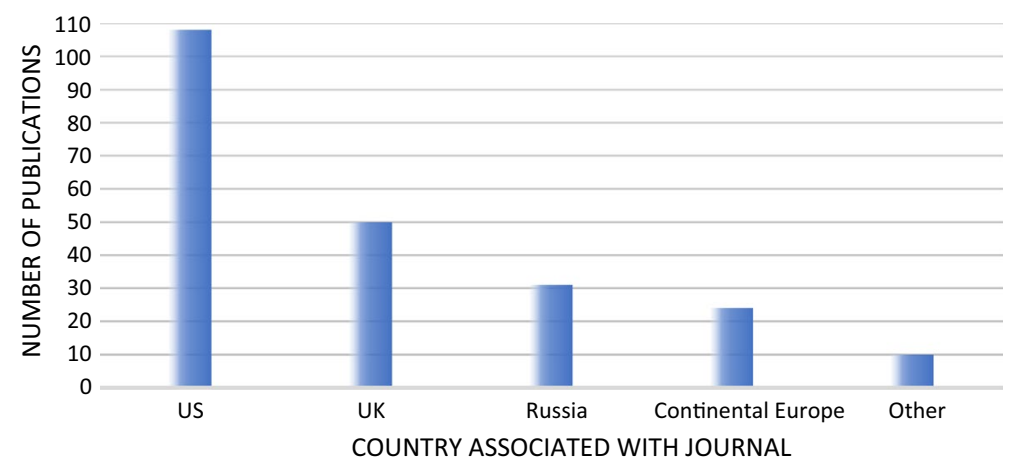

Fig. 3 A bar graph representation of the total number of papers in the network published in different journals in the network. Each journal is associated with the US, UK, Russia, Continental Europe, or other countries not listed before

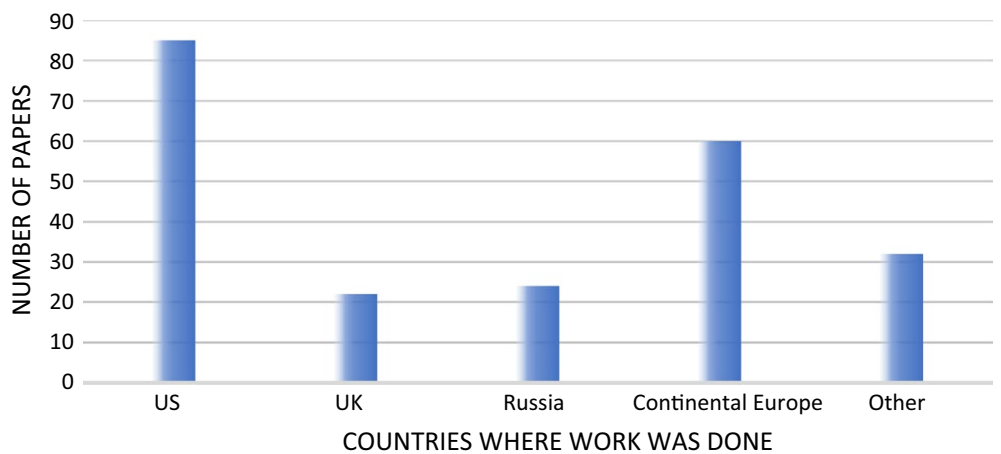

Fig. 4 A bar graph showing countries where work was done versus the number of papers associated with that country in the network

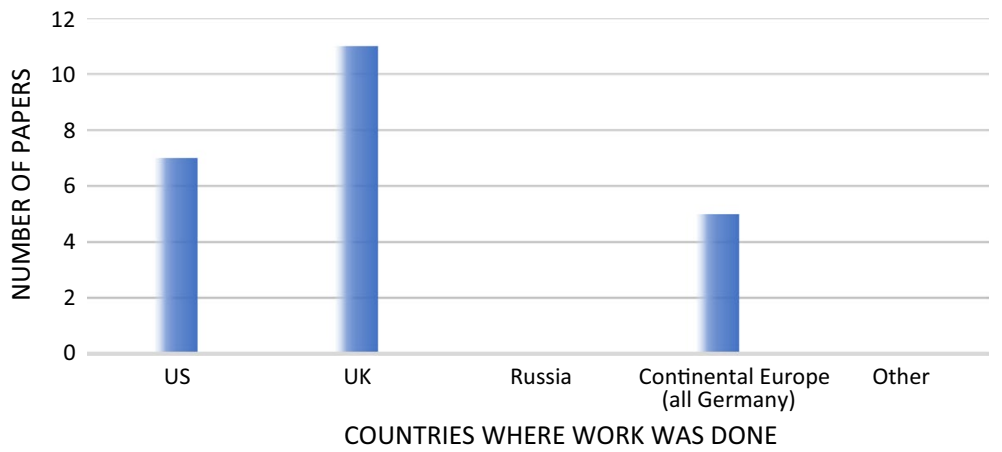

Fig. 5 The number of papers published before 1938 versus where work was done

important works in physics before 1938 but did not seem to be concerned with the gravitational constant until after that time.

After looking at the countries where the work was done, we made smaller citation analysis clusters based on specific countries to look more in depth at the influences countries 


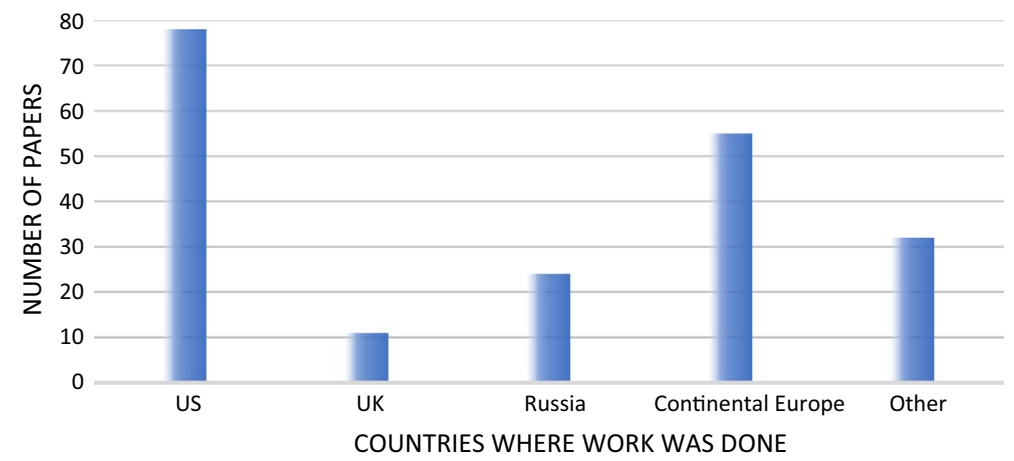

Fig. 6 The number of papers published after 1938 versus where work was done

have on their own papers. We looked at countries that had a small cluster of papers to see if could discover anything intriguing about how countries influence their own work compared to how they influence global work.

Figure 7 shows the small cluster of papers where the work was done in Russia. Many papers in this network do not cite any other papers from Russia nor get cited by papers from Russia. The most important work done by Russia was in the late 90s to early 2000s which matches the overall importance of Russian papers in Figs. 1 and 2.

Fig. 7 Small cluster of papers with work done in Russia

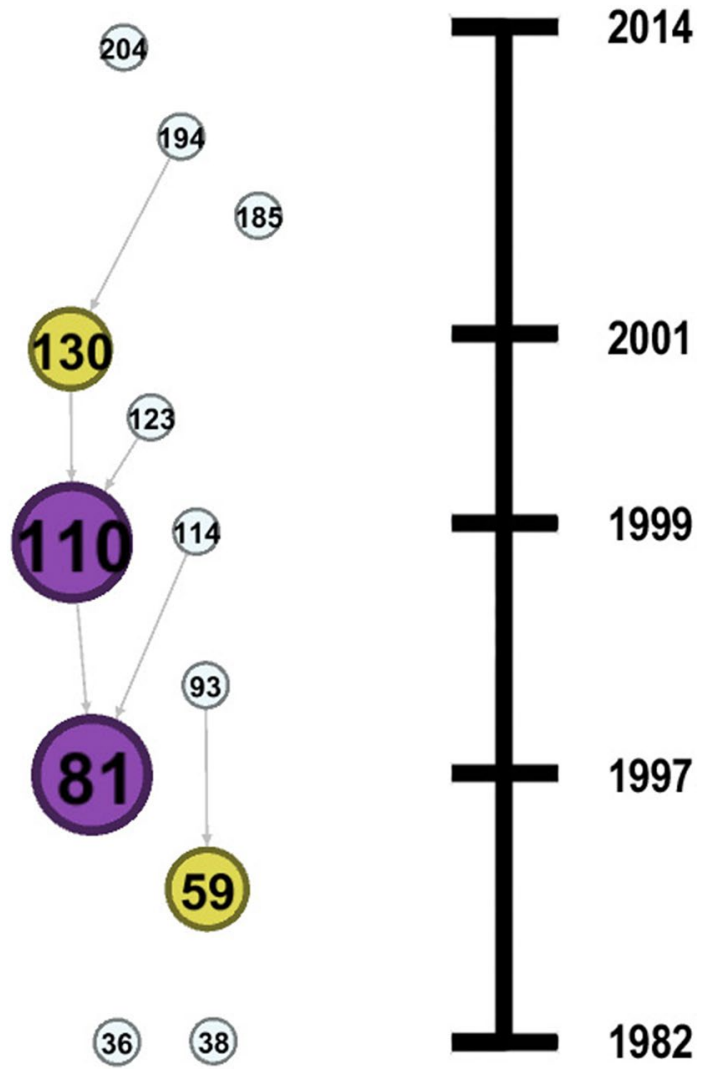


Fig. 8 Small cluster of papers with work done in China

Fig. 9 A small cluster of papers with work done in Germany
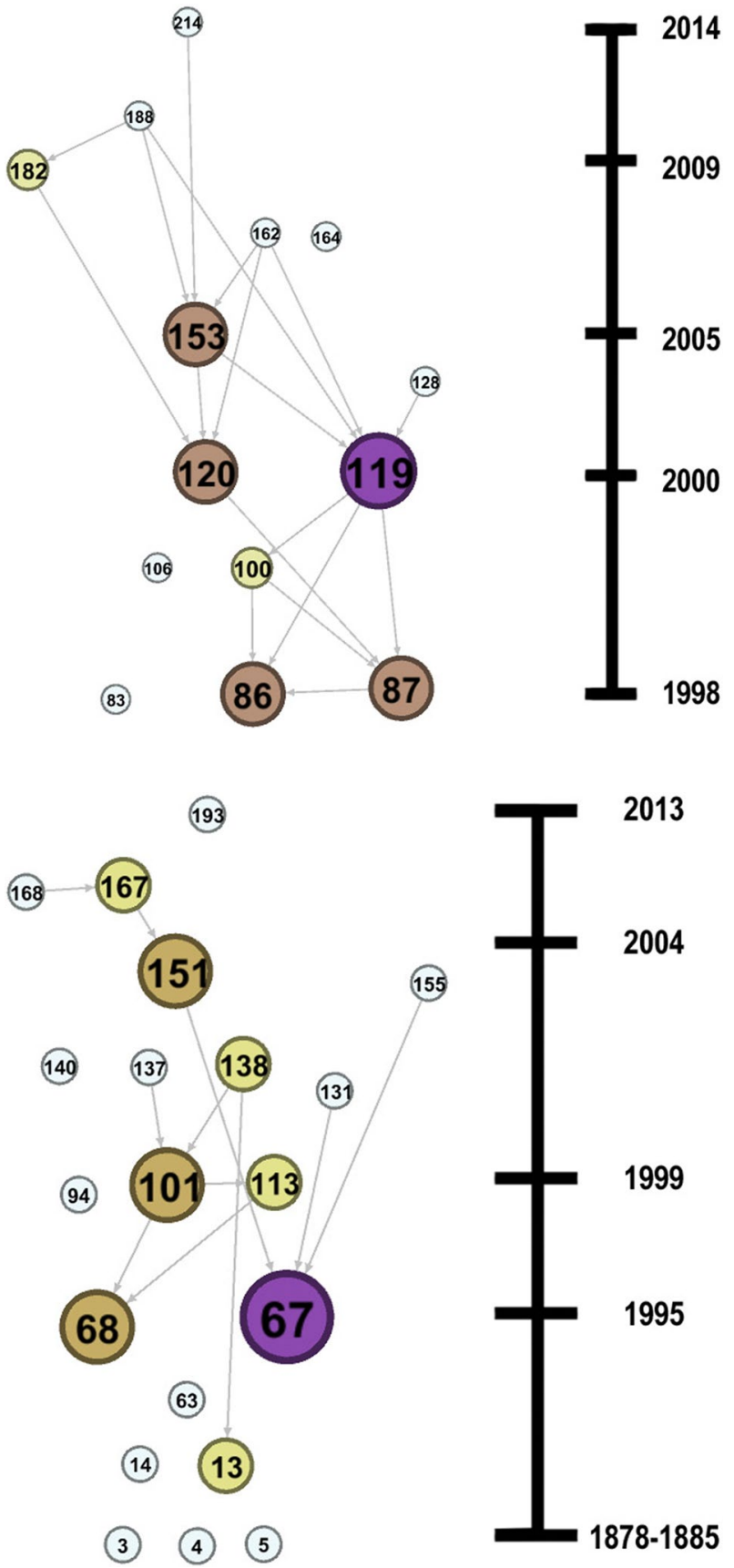

Figure 8 shows a small cluster of papers where the work was done in China. A larger majority of papers from China cite work from within the country given the smaller network only consists of fifteen papers. Many Chinese authored papers also cite US and UK papers. The 
Fig. 10 A small cluster of papers with work done in Switzerland

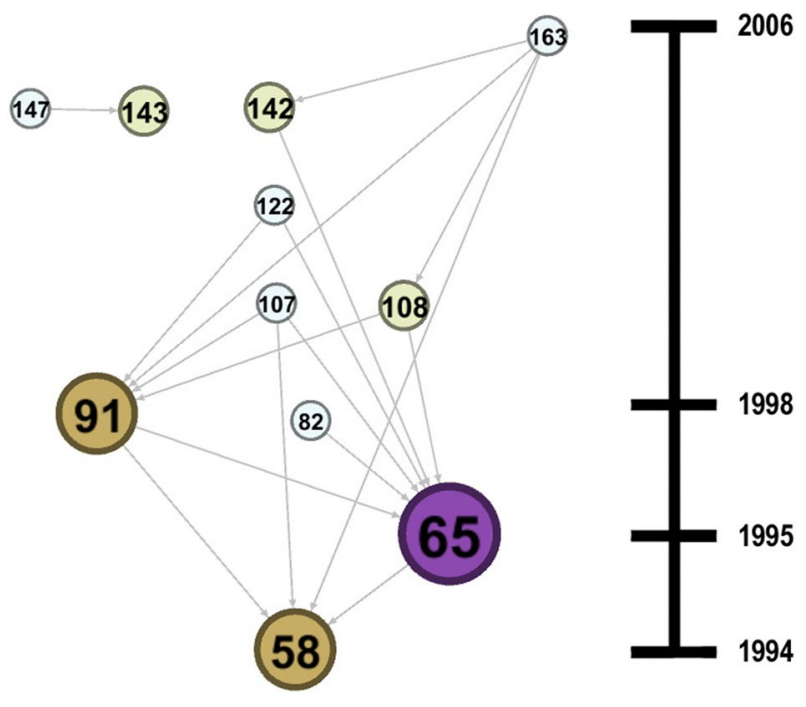

network shows the influence Chinese papers have on each other and the possible influence Chinese papers may have on determining how relevant papers from outside China by citing them.

Figure 9 shows a small cluster of papers where the work was done in Germany. A moderate number of papers cite each other within the network given its size. However, many of the older papers do not seem to be a foundation for work within the contemporary study of Newton's gravitational constant. As mentioned, a lot of work was done in Germany before 1938, but work on the constant did not really gain significance and pick up again until the mid-90s.

Figure 10 shows a small cluster of papers where the work was done in Switzerland. The Swiss network seems to be the most tightly interlinked of the five networks that are broken down into smaller clusters. Every paper in the Swiss network cites or is cited by another paper within the network. Even though papers 58, 65, and 91 are crucial in the Swiss network, in Figs. 1 and 2, they remain only moderately critical.

Figure 11 shows a small cluster of papers where the work was done in France. A smaller than expected number of papers within the network cite other papers from France given the size of the network.

\section{Conclusion}

This paper discusses the implications of the overall trends of a citation analysis done on papers exploring measurements of Newton's gravitational constant. Work slowed down on finding the true value of Newton's $G$ after the early 2000s, but seems to pick back up again beginning in 2014. Looking more closely at the countries associated with journals and countries where the work was done, we found the US published the most papers in both categories. However, many other countries do contribute greatly to experiments involving the constant-especially China, Russia, and UK in later years. Before 1938, the only countries contributing were the US, UK, and Germany. After 1938, many other countries began doing work on Newton's $G$ while the US and UK continued to play prominent roles.

Many countries seem to regard work performed in their own country as the most important and have citation networks that show how often they cite their own work. Although 
Fig. 11 A small cluster of papers with work done in France

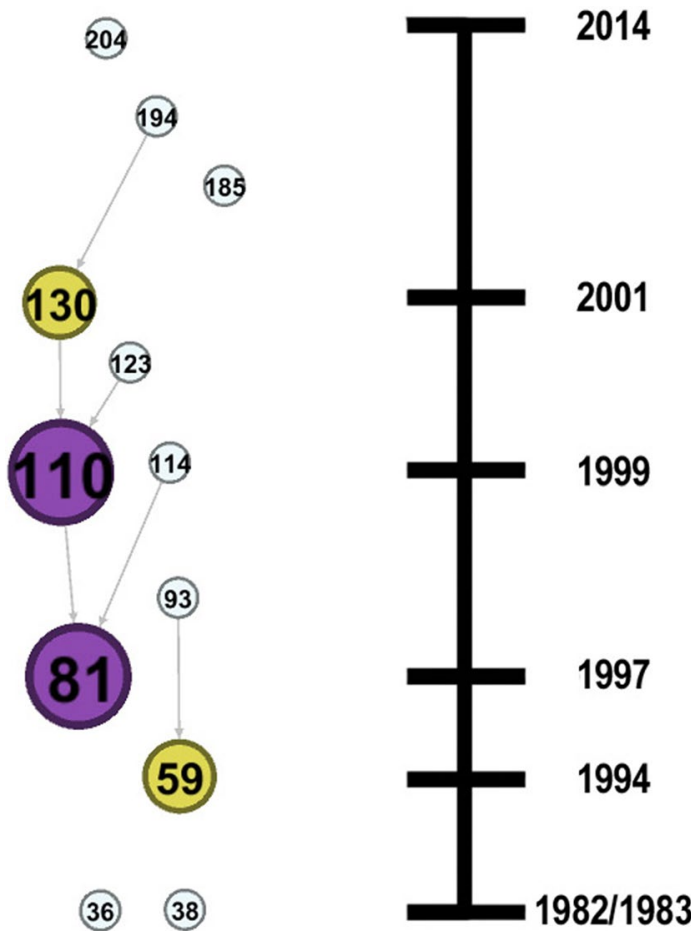

international collaboration occurs, within this network, it is not seen in most of the papers. Popular articles from outside the country seem to be cited, but lesser known papers are only cited by the country that produced them. However, with the National Science Foundation's interest in the gravitational constant in 2016, more international collaboration is to be expected. This could help open the gateway for more experiments and for the sharing of information previously only well known within certain countries.

Further work with this citation network could include separating the network into smaller clusters based on the method used to measure $G$. Work with these clusters could help isolate different values of $G$ and help determine if there is a relationship between values that use the same method of measurement.

Acknowledgements We would like to thank Stephan Schlamminger for providing the papers on which this citation analysis is based. Without him, this paper would have been impossible to create. We would also like to thank the creators of Gephi, the citation analysis program, for creating an intuitive, well designed application for creating graphics.

Open Access This article is distributed under the terms of the Creative Commons Attribution 4.0 International License (http://creativecommons.org/licenses/by/4.0/), which permits unrestricted use, distribution, and reproduction in any medium, provided you give appropriate credit to the original author(s) and the source, provide a link to the Creative Commons license, and indicate if changes were made.

\section{Appendix}

See Table 1. 
Table 1 A table containing the final list of sorted papers given by Schlamminger

0 Newton, I. 1686. Philosophiae Naturalis Principia Mathematica. London

1 Cavendish, H. 1798. Phil. Trans. R. Soc. 88, 469-526

2 Airy, G. B. 1856. Phil. Trans. R. Soc. 146. 297-355

3 von Jolly, Ph. 1878. Ann. Phys. (Leipzig). 5, 112-134

4 von Jolly, Ph. 1881. Ann. Phys. (Leipzig). 14, 331-355

5 König, A and Richarz, F. 1885. Ann. Phys. Chem. 24, 664-668

6 Boys, C. V. 1889. Proc. R. Soc. London. 46, 253-268

7 Boys, C. V. 1894. Nature (London). 50, 517

8 Boys, C. V. 1894. Nature (London). 50, 330-334

9 Boys, C. V. 1894. Nature (London). 50, 366-368

10 Boys, C. V. 1894. Nature (London). 50, 417-419

11 Boys, C. V. 1895. Phil. Trans. R. Soc. 186, 1-72

12 Boys, C. V. 1896. Popular Astronomy. 32, 77-85

13 Braun, C. 1896. Denkschriften der Kaiserlichen Akademie der Wissenschaften, Mathematisch-Naturwissenschaftliche Klasse. 64, 187-258

14 Richarz, F. and Krigar-Menzel, O. 1898. Anhang zu der Abhandlungen der Königlich Preussischen Akademie der Wissenchaften zu Berlin. 1-196

15 Barus, C. 1918. Proc. Nat. Acad. Sci. U.S.A. 4, 338-342

16 Barus, C. 1919. Science. 50, 214-216

17 Barus, C. 1922. Proc. Nat. Acad. Sci. U. S. A. 6, 498-502

18 Barus, C. 1922. Proc. Nat. Acad. Sci. U. S. A. 8, 13-15

19 Barus, C. 1922. Proc. Nat. Acad. Sci. U.S.A. 8, 63-66

20 Barus, C. 1922. Proc. Nat. Acad. Sci. U.S.A. 8, 313-316

21 Eddington, A. S. 1930. Mathematical Proceedings of the Cambridge Philosophical Society. 27, 15-19

22 Heyl, P.R. and Chrzanowski, P. 1930. Res. Natl. Bur. Stand. 5, 1243-1290

23 Heyl, P. R. and Chrzanowski, P. 1942. Nat. Bur. Stand. (U.S.) J. of Res. 29, 1-31

24 Teller, E. 1948. Phys. Rev. 73, 801-802

25 Rose, R. D. et al. Phys. Rev. Lett. 23, 655-658

26 Beams, J. W. 1971. Phys. Today. 24, 34-40

27 Vinti, J.P. 1972. Celest. Mech. 5, 204-254

28 Long, D. R. 1974. Phys. Rev. D. 9, 850-852

29 Smalley, L. L. 1975. Scientific and Technical Aerospace Reports. 13, 1687

30 Luther, G. G. et al. 1976. Atomic Masses and Fundamental Constants. 5, 592-598

31 Greenberger, D. M. and Overhauser, A. W. 1979.Rev. Mod. Phys. 51, 43-78

32 Canuto, V. M. and Hsieh, S. H. 1980. Astrophys. J. 237, 613

33 Farinella, P. et al. 1980. Astrophys. Space Sci. 73, 417-433

34 McQueen, H. W. S. 1981. Phys. Earth Planet. Interiors. 26, P6-P9

35 Stacey, F. D. et al. 1981. Phys. Rev. D. 23, 1683-1692

36 Gillies, G. T. 1982. Rapport BIPM-82/9, 83 pp

37 Luther, G. G. and Towler, W. R. 1982. Phys. Rev. Lett. 48, 121-123

38 Gillies, G. T. 1983. Rapport BIPM-83/1, 135 pp

39 Cohen, E. R. and Taylor, B. N. 1986. Codata Bulletin No. 63, Oxford, New York, Pergamon Press

40 Hills, J. G.1986. Astron. J. 92, 986-988

41 de Boer, H., Haars, H., Michaelis, W. 1987. Metrologia. 28, 397-404

42 Gilles, G. T. 1987. Metrologia. 24, 1-56

43 Nobili, A. M., Milani, A., and Farinella, P. 1987. Phys. Lett. A. 120, 437-441

44 Stacey, F. D. et al. 1987. Rev. Mod. Phys. 59, 157

45 Wright, D. C. 1987. The Obsevatory. 107, 33-34 
Table 1 (continued)

46 Cook, A. 1988. Rep. Prog. Phys. 51, 707

47 t Hooft, G. 1989. Nucl. Phys. B. 382, 436

48 Zumberge, M. A. et al. 1991. Phys. Rev. Lett. 67, 3051

49 Armstrong, T. R., Fitzgerald, M. P. 1992. Meas. Sci. Technol. 3, 1072-1076

50 Sanders, A. J. and Deeds, W. E. 1992. Phys. Rev. D. 46, 480

51 Alekseev, A. D., Bronnikov, K. A., Kolosnitsyn, N. I. et al. 1993. Meas. Technol. 36, 1070-1087

52 Bronnikov, K. A. et al. 1993. Meas. Technol. 36, 845-852

53 Bronnikov, K. A. et al. 1993. Meas. Technol. 36, 951-957

54 Kolosnitsyn, N. I. 1993. Izmer. Tekh. 12, 55-57

55 Kolosnitsyn, N. T. 1993. Meas. Technol. 36, 958

56 Alekseev, A. D., et al. 1994. Meas. Technol. 37, 1-5

57 Bagley, C. H. and Luther, G. G. 1994. Phys. Rev. Lett. 78, 3047-3050

58 Cornaz, A., Hubler, B., and Kündig, W. 1994. Phys. Rev. Lett. 72, 1152-1155

59 Damour, T. and Polyakov, A. M. 1994. Nucl. Phys. 423, 532-558

60 Fitzgerald, M. P., Armstrong, T. R., Hurst, R. B., and Corney, A. C. 1994. Metrologia. 31, 301-310

61 Kolosnisyn, N. I. 1993. Izmer. Tekh. 9, 7-8

62 Kolosnitsyn, N. I., Sinenko, L. A., and Yunoshev, L. S. 1994 Izmer. Tekh. 3, 5

63 Sperling, D. 1994. Ph.D. Dissertation Universität Bonn

64 Fitzgerald, M.P. and Armstrong, T. R. 1995. IEEE Trans. On Instrum. And Measur. 44, 494

65 Hubler, A., Cornaz, A., Kündig, W. 1995. Phys. Rev. D. 51, 4005

66 Kuroda, K. 1995. Phys Rev. Lett. 75, 2796

67 Michaelis, W., Haars, H., Augustin, R. 1995. Metrologia. 32, 267-276

68 Walesch, H., Meyer, H., Piel, H. and Schurr, J. 1995. Trans. Instrum. Meas. 44 (2), 491

69 Yu, V. et. Al. 1995. Meas. Techniques. 38, 1067-1072

70 Bagley, C. H. 1996. Ph.D. Dissertation University of Colorado, Boulder

71 Barrow, J. D. 1996. Mon. Not. R. Astron. Soc. 282, 1397-1406

72 Gundlach, J. H., Adelberger, E.G., Heckel, B. R. and Swanson, H. E. 1996. Phys. Rev. D. 54, R1256-R1259

73 Karagioz, O. and Izmailov, V. 1996. Meas. Technol. 39, 979

74 Kolosnitsyn, N. I., Sinenko, L. A., and Yunoshev, L. S. 1996. Meas. Techniques. 39, 463-465

75 Sanders, A. J. and Gilles, G. T. 1996. Riv. Nuovo Cim. 19 (2), 1-54

76 Alekseev, A. D. et al. 1997. Meas. Techniques. 40, 921-928

77 Romaides, A. J. and Sands, R. W. 1997. Phys. Rev. D. 55, 4532-4536

78 Bagley, C. H. and Luther, G. G. 1997. Phys. Rev. Lett. 78, 3097

79 Gillies, G. T. 1997. Rep. Progr. Phys. 60, 151-225

80 Gundlach, J. H., Adelberger, E.G., Heckel, B. R., Smith, G.L. and Swanson, H. E. 1997. Phys. Rev. Lett. 78, 2524-2526

81 Quinn, T. J., Davis, R. S., Speake, C. C. 1997. Metrologia. 34, 245-249

82 Schurr, J., Nolting, F., and Kündig, W. 1997. Phys. Rev. Lett. 80, 1142-1145

83 Hu, Z. K. and Luo, J. 1998. Phys. Lett. A. 238, 337-340

84 Karagioz, O. and Izmailov, V., and Gillies, G. 1998. Grav. Cosom. 4, 239-245

85 Kestenbaum, D. 1998. Science. 282, 2180-2181

86 Hu, Z. K. and Luo, J. 1998. Phys. Lett. A. 238, 341-343

87 Luo, J., Hu, Z. K., Fu, X. H., Fan, S. H, and Tang, M. X. 1998. Phys. Rev. D. 59 (042001), 1-6

88 Matsumura, S. et. Al. 1998. Phys. Lett. A. 244, 4-8

89 Mohr, P. J. and Taylor, B. N. 2000. Reviews of Modern Physics. 72, 351-495

90 Peters, A. 1998. Ph.D. Dissertation Stanford University

91 Schurr, J., Nolting, F., and Kündig, W. 1998. Phys. Rev. Lett. 80, 1142-1145

92 Schwarz, J. P., Robertson, D. S., Nibeauer, T. M., Faller, J. E. 1999. Science. 282, 2230-2234 
Table 1 (continued)

93 Damour, T. 1999. Meas. Sci. Technol. 10, 467-469

94 Dorobantu. R. 1999. Ph.D. Dissertaion Technische Universität München

95 Falconer, I. 1999. Meas. Sci. Technol. 10, 470-477

96 Falconer, I. 1999. Meas. Sci. Technol. 10, 525-530

97 Fitzgerald, M.P. and Armstrong, T. R. 1999. Meas. Sci. Technol. 10, 429-444

98 Gillies, G. T. 1999. Meas. Sci. Technol. 10, 421-425

99 Gundlach, J. H. 1999. Meas. Sci. Technol. 10, 454-459

100 Hu, Z. K., Luo, JJ., Hsu, H. 1999. Phys. Lett. A. 264, 112-116

101 Kleinevoss, U. et al. 1999. Meas. Sci. Technol. 10, 492-494

102 Kuroda, K. 1999. Meas. Sci. Technol. 10, 435-438

103 Long, J. C., Hilton, W., and Price, J. C. 1998. Nucl. Phys. B539, 23-24

104 Luther, G. G. 1999. Meas. Sci. Technol. 10, 426-426

105 Mansouri, R., Nasseri, F., and Khorrami, M. 1999. Phys. Lett. A. 259, 194-200

106 Ni, W. T. et al. 1999. Meas. Sci. Technol. 10, 495-498

107 Nolting, F., Schurr, J., and Kündig, W. 1999. IEEE Trans. Instrum. Meas. 48, 245-248

108 Nolting, F., Schurr, J., Schlamminger, S. and Kündig, W. 1999. Meas. Sci. Technol. 10, 487-491

109 Peters, A., Chung, K. Y., and Chu, S. 1999. Nature. 400, 849-852

110 Richman, S. J. et al. 1999. Meas. Sci. Technol. 10, 460

111 Ritter, R. C., Winkler, L. I., and Gillies, G.T. Meas. Sci. Tech. 10, 499-507

112 Sanders, A. J. et al. 1999. Meas. Sci. Technol. 10, 514-524

113 Schumacher, A. 1999. Ph.D. Thesis University of Wuppertal, in preparation

114 Speake, C. C. et al. 1999. Phys. Lett. A. 263, 219-225

115 Speake, C. C. et al. 1999. Meas. Sci. Technol. 10, 430-434

116 Speake, C. C. et al. 1999. Meas. Sci. Technol. 10, 508-513

117 Bantel, M. K. and Newman, R. D. 2000. Journ. Alloys and Compounds. 310, 233-242

118 Gundlach, J. H. and Merkowitz, S. M. 2000. Phys. Rev. Lett. 85, 2869-2872

119 Luo, J. and Hu, Z. K. 2000. Class. Quantum Grav. 17, 2351-2363

120 Luo, J., Hu, Z. K., and Hsu, H. 2000. Rev. Sci. Instrum. 71, 1524-1528

121 Melnikov, V. N. 2000. Eprint arXiv:gr-qc/0007067

122 Nolting, F., Schurr, J., Schlamminger, S., and Kündig, W. 2000. Europhysics News. 31, 25-27

123 Quinn, T. J. 2000. Nature. 408, 919-921

124 Sanders, A. J. et al. 2000. Class. Quantum Grav. 17, 2331-2346

125 Alekseev, A. D. et al. 2001. Metrologia. 38, 397-408

126 Gonzalez, A. M. 2001. Science \& Education. 10, 515-543

127 Hoyle, C. D. 2001. Ph.D. Dissertation University of Washington

128 Hu, Z. K., Wang, X. L., and Luo, J. 2001. Chin. Phys. Lett. 18, 7-9

129 Kudryavitskii, M. A. and Karagioz, O. V. 2001. Meas. Techniques. 44, 972-976

130 Quinn, T. J. et al. 2001. Phys. Rev. Lett. 87 (111101), 1-4

131 Wolschin, G. 2001. Physik. 6, 12-18

132 Mohr, P. J. and Taylor, B. N. 2002. Reviews of Modern Physics. 77, 1-107

133 Armstrong, T. R. and Fitzgerald, M. P. 2002. The Ninth Marcel Grossmann Meeting. 1779-1780

134 Gundlach, J. H. and Merkowitz, S. M. 2002. The Nineth Marcel Grossmann Meeting. 1783-1785

135 Karagioz, O. V., Izmailov, V. P., Kudryavitskii, M. A. 2002. Meas. Techniques. 45, 340-344

136 McGuirk, J. M. et al. 2002. Phys. Rev. A. 65 (033608), 1-14

137 Kleinvoss, U. et al. 2002. Precision Electromagnetic Measurements. Conference Digest. 148-149

138 Kleinvoss, U. 2002. Ph.D. Dissertation Universität Wuppertal

139 Kolosnitsyn, N. I. 2002. Meas. Techniques. 45, 331-333 
Table 1 (continued)

140 Lämmerzahl, C. and Dittus, H. 2002. Ann. Phys. (Leipzig). 2, 95-150

141 Melnikov, V. N. and Sanders, A. J. 2002. Ciencia Ergo Sum. 6, 357-370

142 Schlamminger, S. 2002. Ph.D. Dissertation Universität Zürich

143 Schlamminger, S., Holzschuh, E. and Kündig, W. 2002. Phys. Rev. Lett. 89 (161102), 1-4

144 Armstrong, T. R., Fitzgerald, M. P. 2003. Phys. Rev. Lett. 91 (201101), 1-4

145 Fattori, M. et al. 2003. Phys. Lett. A. 318, 184-191

146 Fixler, J. B. 2003. Ph.D. Dissertation Yale University

147 Kündig, W. and Schlamminger, S. 2003. Phys. Rev. Lett. 91 (109002), 1

148 Datta, T. et al. 2003. Phys. Rev. Lett. 91 (109001), 1

149 Fattori, M. 2004. Ph.D. Dissertation Università Delgi Studi Di Firenze

150 Kolosnitsyn, N. I. and Melnikov, V. N. 2004. General Relativity and Gravitation. 36, 1619-1624

151 Michaelis, W., Melcher, J., and Haars, H. 2004. Metrologia. 41, L29-L32

152 Baldi, P. et al. 2005. Phys. Rev. D. 71 (022002), 1-5

153 Hu, Z. K., Guo, J. Q., and Luo, J. 2005. Phys. Rev. D. 71 (127505), 1-3

154 Kapner, D. J. 2005. Ph.D. Dissertation University of Washington

155 Michaelis, W., Melcher, J., and Haars, H. 2004. Metrologia. 42, 67

156 Bertoldi, A. et al. 2006. Eur. Phys. J. D. 40, 271-279

157 Cashen, M. T. et al. 2006. Optics Letters. 34, 347-349

158 Choi, K. Y. 2006. Ph.D. Dissertation University of Washington

159 Mohr, P. J., Taylor, B. N., and Newell, D. B. 2008. Rev. Mod. Phys. 80, 633-730

160 Bertoldi, A. et al. 2006. The Eleventh Marcel Grossmann Meeting. 2519-2529

161 Kolosnitsyn, N. I. and Kononogov, S. A. 2006. Meas. Techniques. 49, 741-744

$162 \mathrm{Hu}$, Z. K., Liu, Q., and Luo, J. 2006. Front. Phys. China. 4, 449-457

163 Schlamminger, S. et al. 2006. Phys. Rev. D. 74 (082001), 1-25

164 Wang, D. H., Luo, J., and Luo, K. 2006. Rev. Sci. Instum. 77 (104501), 1-4

165 Biedermann, G. 2007. Ph.D. Dissertation Stanford University

166 Dimopoulos, S. et al. 2007. Phys. Rev. Lett. 98 (111102), 1-4

167 Dose, V. 2007. Meas. Sci. Technol. 18, 176-182

168 Dose, V. 2007. Meas. Sci. Technol. 18, 2281-2282

169 Fixler, J. B. et al. 2007. Science. 315, 74-77

170 Kolosnitsyn, N. I., Kononogov, S. A., and Melnikov, V. N. 2007. Meas. Techniques. 50, 565-574

171 Lamporesi, G. et al. 2007. Rev. Sci. Instrum. 78 (075109), 1-7

172 Ray, S. et al. 2007. Eprint arXiv:0705.1836

173 Vitushkin, L. and Wolf, P. 2007. International Journal of Modern Physics D. 16, 2287-2295

174 Willink, R. 2007. Meas. Sci. Technol. 18, 2275-2280

175 Barrow, J. D. 1998. Current Topics in Astrofundamental Physics: Primordial Cosmology. 296

176 Adelberger, E.G. et al. 2008. Progress in Particle and Nuclear Physics. 62, 102-134

177 Lamporesi, G. et al. 2008. Phys. Rev. Lett. 100 (050801), 1-4

178 Pollack, S. E., Schlamminger, S., Gundlach, J. 2008. Phys. Rev. Lett. 101 (071101), 1-3

179 Cronin, A. D., Schmiedmayer, J., and Pritchard, D. E. 2009. Rev. Mod. Phys. 81, 1051-1129

180 Cross, W. D. 2009. Ph.D. Dissertation University of California, Irvine

181 Galli, S. et al. 2009. Phys. Rev. D. 80 (023508), 1-7

182 Luo, J. et al. 2009. Phys. Rev. Lett. 102 (240801), 1-4

183 Milyukov, V. K., Tao, C., and Mironov, A. P. 2009. Gravitation and Cosmology. 15, 65-68

184 Sorrentino, F. et al. 2009. Journal of the European Optical Society. 4 (09025), 1-5

185 Davis, R. 2010. Nature. 468, 181-183

186 Parks, H. V. and Faller, J. E. 2010. Phys. Rev. Lett. 105 (110801), 1-4 
Table 1 (continued)

187 Reich, E. S. 2010. Nature. 466, 1030

188 Tu, L. C. et al. 2010. Phys. Rev. D. 82 (022001), 1-36

189 Ducheyne, S. 2012. Science \& Education. 21, 87-108

190 McGuinness, H. J., Rakholia, A. V., and Biedermann, G. W. 2012. Appl. Phys. Lett. 100 (011106), 1-4

191 Milyukov, V. and Fan S. 2012. Gravitation and Cosmology. 18, 216-224

192 Faller, J. E. 2014. Proceedings, 2013 IAG Symposium on Terrestrial Gravimetry: Static and Mobile Measurements. 5

193 Hagedorn, D. 2013. Ann. Phys. (Berlin). 525, 720-727

194 Quinn, T. et al. 2013. Phys. Rev. Lett. 111 (101102), 1-5

195 Bartlett, D.F. 2014. Phil. Trans. R. Soc. A. 372 (20140021)

196 Cowen, R. 2014. Nature. https://www.nature.com/news/quantum-method-closes-in-on-gravitation (Accessed August 1, 2018)

197 Faller, J. E. 2014. Phil. Trans. Soc. A. 372 (21040023)

198 Gibney, E. 2014. Nature. 514, 150-151

199 Li, Q. et al. 2014. Phil. Trans. R. Soc. A. 372 (20140141)

200 Newman, R. et al. 2014. Phil. Trans. R. Soc. 372 (20140025)

201 Overduin, J. et al. 2012. Class. Quantum Grav. 29 (184012)

202 Parks, H. V. and Faller, J. E. 2014. Phil. Trans. R. Soc. A. 372 (20140024)

203 Prevedelli, M. et al. 2014. Phil. Trans. R. Soc. 372 (20140030)

204 Quinn, T. 2014. Nature. 505, 455

205 Quinn, T., Speake, C., and Davis, R. 2014. Phys. Rev. Lett. 113 (039901), 1

206 Speake, C. and Quinn, T. 2014. Physics Today. 67, 27

207 Quinn, T. et al. 2014. Phil. Trans. R. Soc. A. 372 (20140032)

208 Quinn, T. and Speake, C. 2014. Phil. Trans. R. Soc. A. 372 (20140253)

209 Rosi, G. et al. 2014. Nature. 510, 518-521

210 Rothleitner, C. and Francis, O. 2014. Rev. Sci. Instrum. 85 (044501)

211 Schlamminger, S. 2014. Nature. 510, 478-480

212 Schlamminger, S. et al. 2014. Phil. Trans. R. Soc. A. 372 (20140027)

213 Wood, B. M. 2014. Phil. Trans. R. Soc. A. 372 (20140029)

214 Xue, C. et al. 2014. Phil. Trans. R. Soc. A. 372 (20140031)

215 Anderson, J. D. et al. 2015. EPL. 110 (10002)

216 Anderson, J. D. et al. 2015. EPL. 111 (30003)

217 DeSalvo, R. 2015. Phys. Lett. A. 379, 1202-1205

218 Klosser, W. J. et al. 2016. American Journal of Physics. 84, 234

219 Rothleitner, C. and Schlamminger, S. 2015. Physik Journal. 14, 37-42

220 Schlamminger, S., Gundlach, J. H., and Newman, R. D. 2015. Phys. Rev. 91, 121101

221 Benish, R. 2016. http://vixra.org/abs/1612.0341 (Accessed August 1, 2018)

222 Feldman, M. R. et al. 2016. Class. Quantum Grav. 33 (125013), 1-12

223 Schmöle, J. et al. 2016. Eprint arXiv:1602.07539v1

Each number corresponds to a paper represented in Figs. 1, 2, 7, 8, 9, 10, and 11 